\title{
Methhaemoglobinaemia - a case of an elderly patient with indoxacarb poisoning
}

\author{
Aravinthan A, Pratheepan $G J$, Sivansuthan $S$, Gajanthan $R$
}

Teaching Hospital, Jaffna

\section{Introduction}

Indoxacarb poisoning is a well-known cause for methaemoglobinemia. It's an insecticide that is considered a safe substitute for organophosphate insecticides [1]. It's main action is to block sodium channels in the nervous system of insects causing neurological manifestations [1,2].

This case illustrates the occurrence of methaemoglobinemia following ingestion of indoxacarb in an attempt of deliberate selfharm. Indoxacarb is an oxidative insecticide and human toxicity include blurred vision, skin sensitization and alteration in blood counts. [5]. This case highlights the early recognition of methaemoglobinemia in cases of indoxacarb poisoning.

\section{Case Report}

A 70 year old male with a background of type II Diabetes mellitus, hypertension, dslipidemia and bronchial asthma presented to the emergency unit with a history of ingestion of an unknown poison 12 hours before, with drowsiness and vomiting.

On examination, he was afebrile, PR- 92 bpm, BP 160/90, GCS $12 / 15$, pupils were mildly dilated, reactive to light and $\mathrm{SPO}_{2}$ was $82 \%$ on 51 of oxygen. Organophosphate poisoning was suspected and he was treated with atropine $0.2 \mathrm{mg} / \mathrm{h}$ and pralidoxime $200 \mathrm{mg} / \mathrm{h}$ infusion were initiated. He was mechanically ventilated due to persistent desaturation while being treated for possible aspiration. He was treated with IV Co-Amoxiclav, IV metronidazole and nebulized salbutamol.

Peripheral cyanosis was noticed with the arterial $\mathrm{PaO}_{2}-154 \mathrm{~mm} / \mathrm{Hg}$ on $\mathrm{FiO}_{2}-100 \%$, while $\mathrm{SPO}_{2}$ reading was on the pulse oxymeter was $80 \%$. Blood during venipuncture was brownish color. Aetiologically indoxacarb poisoning was suspected as the cause for methemoglobinemia at a level of $8.55 \mathrm{~g} / \mathrm{dl}$ with the control being $0.05 \mathrm{~g} / \mathrm{dl}$. He was treated with Methylene blue $60 \mathrm{mg}$ in $100 \mathrm{ml}$ normal saline over $15 \mathrm{~min}$, repeated in 12 hours and a dramatic improvement was noted.
This patient was also managed for ventilator associated pneumonia and had an uneventful recovery.

\section{Discussion}

Methaemoglobinaemia is a common presentation of indoxacarb poisoning. Methaemoglobin is generated by oxidation of haem iron to the ferric state, causing a characteristic bluish - brown colour resembling cyanosis [4]. Methaemoglobin has a high affinity to oxygen, which is not delivered to tissues and the oxygen dissociation curve is shifted towards the left $[1,4]$. Methaemoglobinemia should be suspected in patients with hypoxic symptoms and low $\mathrm{SPO}_{2}$ who appear cyanotic, though $\mathrm{PaO}_{2}$ levels on $\mathrm{ABG}$ analysis are sufficiently high to fully saturate the haemoglobin. Bluish- brown appearance of freshly drawn blood may be a critical clue [1]. The methaemoglobin levels are usually less than $0.5 \%$. Cyanosis usually manifests at a level of $15 \%$ and treatment is warranted at levels above $30 \%$. Levels more than $60 \%$ is considered lethal [1].

Treatment includes ceasing exposure to the offending agent, correcting metabolic abnormalities, administrating methylene blue at a dose of $1-2 \mathrm{mg} /$ $\mathrm{kg}$ loading dose over 30 to 60 minutes and then twice daily [4].

Methylene blue gets reduced to leucomethylene blue which in turn reduces the methaemoglobin by NADPH reductase. Methylene blue also reduces the half-life of methaemoglobin. The main side effect of methylene blue is haemolytic anemia and a mild haemolysis was noted in this case.

\section{References}

1. Rathnayaka RM MKN, Wijekoon C N, Sugathapala A G H, Ranathunga P E A N. Indoxacarb - a rare cause of poisoning, Journal of the Ceylon College of Physicians, 2016, 47, 46-47

2. McKinley N, Kijima S, Cook G, Sherrod D. Avaunt (indoxacarb): A new mode of action insecticide for control of several key orchard pests. Proceedings of the 76th Annual 
3. Western Orchard Pest and Disease Mana gement Conference 9-11 January 2002 published by Washington State Univ., Pullman, Washington. http://entomology.tfrec.wsu.edu/ wopdmc/2002PDFs/Rep02\%20 Chemical \%20 McKinley.pdf (Downloaded 1st December 2014)

4. Shihana F, Dissanayake D., Buckley NA, Dawson AH. A Simple Quantitative Bedside Test to Determine Methemoglobin.Annals of Emergency Medicine 2010; 55: 184-9.
5. Prasanna L, Rao SM, Singh V, et al.. Indoxacarb poisoning: An unusual presentation as methemoglobinemia. Indian Journal of Critical Care Medicine 2008; 12: 198-200.

6. Kyubok Jin. Rhabdomyolysis, methae moglobinemia and acute Kidney injury after indoxacarb poisoning. Clinical Toxicology 2012; 50: 227. 